\title{
A ANÁLISE BERGSONIANA DO SOCIAL ENTRE NATUREZA E CULTURA: PSICOLOGIA, BIOLOGIA E FILOSOFIA MORAL À LUZ DA DURAÇÃO
}

\author{
Débora Morato Pinto \\ UFSCar/CNPq
}

\begin{abstract}
Resumo: Este texto tem como objetivo descrever aspectos da filosofia moral de Bergson em sua relação direta com a renovação de metafísica estabelecida pelo filósofo. Mais explicitamente, buscamos elucidar como a biologia compreensiva de $A$ Evolução Criadora funda a análise da moralidade na obra As Duas Fontes da Moral e da Religião, ao delinearmos as variáveis teóricas que se mobilizam na elaboração da noção de todo da obrigação (as quais envolvem o hábito e o instinto, noções que pertencem ao campo da psicologia e da biologia respectivamente). Nossa hipótese mais geral defende que a incorporação de avanços das ciências sociais no início do século XX é a etapa prevista e definitiva de uma filosofia que se relacionou intimamente com os avanços das ciências naturais (e de seu rico material empírico), especificamente as biológicas, configurando também um programa de diálogo com ciências eminentemente humanas.
\end{abstract}

Palavras-chave: Bergson; Consciência; Vida; Moral; Memória; Hábito.

\begin{abstract}
This text aims to describe aspects of Bergson's moral philosophy in its direct relationship with the new metaphysics established by the philosopher. More explicitly, we seek to elucidate how the understanding biology of Bergson' Creative Evolution bases the analysis of morality in the work The Two Sources of Morals and Religion, We defend the hypothesis that the incorporation of advances in the social sciences at the beginning of the twentieth century is the definitive stage of a philosophy that has been closely related to the advances of the natural sciences (and its rich empirical material).
\end{abstract}

Keywords: Bergson; Consciousness; Life; Moral; Memory; Habit.

A despeito de suas recorrentes críticas ao espírito de sistema e, consequentemente, à tradição filosófica ocidental, Bergson não deixou de elaborar algo como uma doutrina, composta pela articulação inovadora entre uma teoria do conhecimento de base psicológica (construída em torno da análise da consciência) e uma metafísica do tempo - ou antes da durée centrada na noção de vida, ou seja, de base biológica. Essa doutrina resultante configura, como sabermos, um espiritualismo renovado, que pretende superar os impasses da tradição derivados, segundo esse diagnóstico crítico, da falta de 
instrumentos teóricos adequados à apreensão fiel da natureza, $\mathrm{O}$ equívoco das correntes filosóficas consistiu, mesmo através de caminhos distintos, em negligenciar a distinção entre matéria e espírito, estabelecendo na física o fio condutor para a filosofia da natureza - o que significa, em última instância, separar radicalmente a natureza e o espírito ${ }^{1}$. Ao explicitar que semelhante tentativa falha ao estender ao espírito aquilo que pertence apenas à matéria, perdendo de vista o 'que o espírito tem de propriamente espiritual' (BERGSON, 2009, p.40)2 ${ }^{2}$ o filósofo deixa entrever que o problema não está propriamente no caráter sistemático do pensamento da tradição, mas antes no equívoco de tratar o real sem dar conta das diferenças de natureza que o constituem. Daí os seus refinados procedimentos de diferenciação de mistos que recuperam a dinamicidade, a heterogeneidade e a continuidade próprias ao espiritual, ou à duração, características negligenciadas pelos sistemas fundados numa racionalidade adequada de direito e de fato à materialidade que tende ao homogêneo, ao estático e ao descontínuo.

Se podemos falar de sistema filosófico no caso de Bergson, entendase por isso a construção de uma doutrina cuja unidade pode ser primeiramente definida por uma posição crítica: a recusa ao equívoco de base que consiste em tratar como objetos homogêneos dimensões da realidade que são de natureza distinta. Nesse contexto, ele renova as disciplinas filosóficas, sem, entretanto, desprezá-las como etapas que, adequadamente articuladas, culminam numa teoria do espírito como ser-em-duração. A renovação mencionada tem alguns pontos notáveis para que se a compreenda, entre os quais a compreensão dos atos originários de conhecimento como processos vitais e a releitura da biologia como etapa internamente constitutiva da descida à terra de que necessita uma metafísica positiva. É, portanto, no entrelaçamento da psicologia com a biologia que reside o modo próprio de renovação das 'disciplinas filosóficas' por Bergson. Teoria do conhecimento e metafísica devem então buscar um solo empírico, e sua rearticulação se efetiva exatamente à luz da dimensão concreta

\footnotetext{
${ }^{1} A$ crítica de fundo à filosofia sistemática reside então na denúncia de que o espírito não pode, sob risco de perdermos sua essência própria, submeter-se às categorias da física, tal como a metafísica de base puramente intelectual busca fazer ao deixar-se levar por seu funcionamento natural. Esse prolongamento sem crítica da inteligência produzirá apenas uma "física do espírito, decalcada da física do corpo; em conjunto, essas duas físicas constituirão um sistema completo da realidade, o que se denomina por vezes uma metafísica" (BERGSON, 2009, p.40).

2 Utilizamos as obras de Bergson em francês, no caso de La Pensée et le Mouvant e de Les deux sources de la morale et de la religion, sempre as edições da PUF organizadas por Frédéric Worms. As citações dessas obras são traduzidas por nós. No caso de Matéria e Memória e A Evolução Criadora, citamos diretamente as boas traduções da editora Martins Fontes. Ver referências bibliográficas ao final do texto,
} 
que deve dirigi-las ${ }^{3}$. A teoria bergsoniana do conhecimento transforma-se, nesse contexto, numa filosofia da consciência de base psicológica. Trata-se de analisar a consciência humana em sua riqueza de conteúdo e de níveis de tensão, e em sua inseparabilidade do corpo, o que se efetiva pela descrição minuciosa dos atos de reconhecimento atento pelos quais agimos no mundo, resultantes da união entre conteúdo espiritual e mecanismos cerebrais que responde pela atenção à vida - a adaptação e a luta pela vida dirigem, portanto, nossos atos mentais.

Nesse contexto, Bergson pode passar da teoria do conhecimento à metafísica na exata medida em que confere valor biológico à psicologia da memória, condição para encontrar o núcleo teórico de sua filosofia inteira na refundação do evolucionismo indicada por ele como horizonte de suas mais profundas especulações. Ao assim proceder, segue certa partição comum de áreas de investigação filosófica, com a diferença, essencial em muitos sentidos, de que elas são levadas a cabo em torno de centros empíricos que envolvem linhas de fatos, explicações conceituais, análises e resultados produzidos no campo das ciências. Esse viés próprio conferido a cânones tradicionais presentes na história da filosofia é confirmado pelo que foi reservado à sua última obra a investigação filosófica sobre os fundamentos da moral e da religião. O estudo desses dois tipos de fenômenos, morais e religiosos, é condicionado pela metafísica elaborada anteriormente, e se realiza como prolongamento da interpretação filosófica da biologia evolutiva. Desse centro empírico em torno do qual gira $A$ Evolução Criadora, Bergson parte então para outro campo, o que lhe exige dialogar, incorporar e criticar o trabalho das ciências ditas sociais.

Os fundamentos da moral à luz da metafísica da vida são estabelecidos no interior da mais polêmica obra de Bergson, em que novos dualismos são percorridos sempre na chave da busca de sua união. Trata-se, em As Duas Fontes da Moral e da Religião, de contrapor uma forma de viver em sociedade, pautada pelos grupos e sua sobrevivência, a outra forma possível ou ideal, em que o lastro do corpo social seria a fraternidade advinda do sentimento de pertencimento à Humanidade enquanto tal. As sociedades humanas, cuja origem está na própria tendência da animalidade forjada no movimento vital - ou seja, na evolução biológica - surgem como prerrogativas da espécie e marcadas pela dualidade própria do impulso de criação que se

\footnotetext{
${ }^{3} \mathrm{~A}$ teoria bergsoniana do conhecimento articula-se em sua segunda obra, Matéria e Memória, através da análise de processos psicológicos que apontam no ato de reconhecimento atento o fenômeno iluminador para a solução do dualismo clássico. A psicologia da memória elaborada para explicar esse processo possibilita, ao seguir tal viés, a compreensão de que o conteúdo eminentemente espiritual no homem, o seu passado, sua história ou a totalidade de suas lembranças, depende do corpo e institui-se como dimensão da natureza.
} 
dissocia ao contato com a matéria. A dualidade em questão, entre a pura conservação e a abertura - arriscada - à criação e à transformação, reaparece então nos modos de vida coletivos pelos quais os homens se relacionam historicamente. Delimitados por essa dualidade, como de resto ocorre em todas as investigações de Bergson dedicadas a um problema filosófico clássico, os fundamentos da moralidade devem imperativamente ser investigados à luz das lições ensinadas pela observação da vida coletiva, isto é, em contato com o material próprio às ciências sociais. E, eis o essencial, enquanto investigação filosófica cuja linha mestra reside na superação da racionalidade científica que confia na estrutura estática revelada por uma objetivação sem tempo, em nome de uma análise conformada pela dinamicidade do real e por isso mesmo de natureza genética, trata-se para a filosofia bergsoniana de substituir a noção de fundamentos pela de fontes.

É assim que a análise das sociedades abre o trajeto de Duas Fontes, oferecendo-nos certa concepção dos fenômenos sociais cujo fundo teórico é a metafísica da vida elaborada nas obras anteriores. A essência da vida como criação e liberdade funda, assim, a filosofia moral bergsoniana. Pretendemos aqui descrever aspectos dessa filosofia que dependem da retomada da metafísica, ao mesmo tempo em que determinam os seus prolongamentos mais originais e mesmo polêmicos. Mais explicitamente, buscamos elucidar como a biologia compreensiva de $A$ Evolução Criadora funda a análise da moralidade na última obra, ao delinearmos as variáveis teóricas que se mobilizam na elaboração da noção de todo da obrigação (as quais envolvem o hábito e o instinto, noções que pertencem ao campo da psicologia e da biologia respectivamente). Por esse viés, objetivamos fornecer o quadro inicial que delimita os marcos a partir dos quais a filosofia moral de Bergson dialogará com a sociologia e a antropologia da primeira metade do século XX. Nossa hipótese mais geral defende que a incorporação de avanços de tais ciências, ou seja, o diálogo crítico e produtivo com as ciências ditas sociais é o último passo de uma filosofia que se relacionou intimamente com os avanços das ciências naturais (e de seu rico material empírico), especificamente as biológicas, para desse modo colher os benefícios da relevância que Bergson soube conferir a uma análise filosófica consequente e profunda sobre o corpo e, mais amplamente, sobre o bios.

É importante esclarecer, para o que propomos aqui, de que modo a relação entre a filosofia de Bergson e as ciências do seu tempo nutre o solo de seu projeto teórico total. As duas primeiras obras do autor dialogam de maneira crítica e positiva (na medida em que ao menos Matéria e Memória 
incorpora resultados das pesquisas sobre as afasias) com a psicologia nascente e a neurofisiologia em plena ebulição ao final do século XIX, e a terceira pode ser lida como a mais importante interpretação filosófica, de âmbito metafísico, da biologia evolutiva. Retomemos algumas consequências desse trajeto. $\mathrm{O}$ mérito de Bergson a ser realçado consiste na antecipação da retomada da filosofia da consciência à luz das questões que certas inovações da ciência necessariamente colocavam e, o que é mais crucial, ter explorado o vínculo entre a análise psicológica e a reflexão dos biólogos qualificando-o como intrínseco. Ao estabelecer esse vínculo, ele pode retomar em novas bases as aspirações metafísicas (em desuso ou mesmo solapadas a partir da 'revolução transcendental' de Kant) na exata medida em que a Vida se apresenta como objeto enigmático e indispensável ao saber. $\mathrm{O}$ trajeto de $A$ Evolução Criadora ilustra todos esses fatores ao elaborar o projeto metafísico por meio de uma cosmologia e tomar como centro dessa elaboração o estudo concreto dos fenômenos biológicos, assumindo que a vida se aproxima da consciência em devir ou, dito de outra maneira, que o movimento vital tomado em sua totalidade evolui ao modo de uma consciência, tomada aqui como puro querer ou corrente que avança no sentido da libertação frente à materialidade. Ora, tal empresa só se torna possível, em atendimento às exigências da intuição como método, na medida em que o filósofo pode reinterpretar os fatos compilados pela biologia evolutiva, debatendo com os seus teóricos e liberando o trabalho dos cientistas de categorias prévias que impediam a apreensão fiel do sentido dos fenômenos exaustivamente analisados por eles.

Mas leitura de $A$ Evolução Criadora antecipa também algumas contribuições significativas para debates atuais da antropologia. A reinterpretação do evolucionismo ali efetivada caminha passo a passo através do diálogo com o material empírico, e encontra a significação da vida como criação precisamente porque o processo dissociativo em linhagens de espécies permite entrever em que sentido as tendências divergentes se complementam. A análise da história do trajeto do elã vital, em que vegetais e animais apontam para uma origem comum e uma complementaridade em favor da ampliação crescente da capacidade de executar movimentos espontâneos e livres, inclui como etapa a dissociação da animalidade em duas tendências divergentes, a linhagem da inteligência e a do instinto. Nesse momento da história da vida, encontramos a descrição do lugar do homem no âmbito da animalidade que o envolve e o precede, e ao compartilhar com a biologia o material por ela produzido, de ricas conotações filosóficas, Bergson elabora sua solução para o problema da diferença de natureza entre os homens e os outros seres vivos. A diferença antropológica ressurge então na base da faculdade que nos define como espécie, a inteligência (e que evidencia a continuidade da linha da 
animalidade que se diferencia em duas tendências, intelectual e instintiva), contanto que seja explicitado aquilo que efetivamente a inteligência (linguagem e a técnica nela compreendidas como seus 'principais produtos') aporta à humanidade.

Qual é, então, a contribuição definitiva que a dissociação da vida em seres inteligentes traz à nossa espécie? Em linhas gerais, e mobilizando argumentos desenvolvidos em Matéria e Memória sobre a relação entre cérebro e consciência, o filósofo defende que, no ser humano, potencializa-se a base material da inteligência, o sistema nervoso altamente complexo ou conjunto de mecanismos sensório-motores em conexões quase que infinitamente variadas, que lhe permitem, por essa variabilidade mesma, a liberação da atenção em relação aos perigos, ameaças e necessidades impostos pela sobrevivência. $\mathrm{O}$ que se liberta nessa história é a função limitada da consciência, que passa a interessar-se pelo que ultrapassa a mera necessidade vital. Da atenção à vida, a consciência passa à mobilização de seus conteúdos para finalidades não imediatas ou práticas. A diferença entre mecanismos dominantes nos animais e nos homens passa a ser qualitativa, porque suas consequências derivam na inventividade e na liberdade humanas: se o animal inteligente em geral pode usufruir das vantagens de um mecanismo que nele se desenvolve, obtendo do resultado da fabricação instrumentos adaptativos que serão repetidos indefinidamente, no animal humano a vantagem do objeto fabricado se torna irrelevante perto 'das ideias novas, dos sentimentos novos que a invenção pode fazer surgir por todos os lados, como se tivesse como efeito especial nos alçar acima de nós mesmos e, ao fazê-lo, ampliar nosso horizonte' (BERGSON, 2005, p.198).

Notemos então que uma primeira aproximação com as ciências sociais está inserida no coração da interpretação da biologia. Com efeito, a diferença antropológica terá a sua significação metafísica determinada no terceiro capítulo da obra, quando a gênese concomitante da matéria e da inteligência redefinirá a forma bumana como aquela em que a consciência conseguiu prosseguir o seu caminho, portanto, como a própria liberdade 4 . Retomamos brevemente essas considerações apenas para delinear uma consequência que nos importa para o estudo da moral: é na medida em que Bergson pode reinterpretar a biologia que ele pode oferecer o mote de uma antropologia, e essa transição se efetiva sem salto no escuro ou ruptura

${ }^{4} \mathrm{O}$ capítulo consiste no âmago da metafísica da vida, e assim da própria filosofia bergsoniana, e somente ali a significação da vida, envolvendo a própria significação do homem, recebe sua versão final. O homem ganha o estatuo de ser moral que retoma a criação, e assim "continua indefinidamente 0 movimento vital" (BERGSON, 2005, p.288). 
inexplicável, exatamente porque deriva da compreensão da evolução vital como consciência, isto é, duração. As pinceladas sobre o trajeto de A Evolução Criadora aqui elencadas permitem entrever uma dimensão fundamental do bergsonismo, sua capacidade de compartilhar com a ciência os mesmos alvos ou objetos - e talvez, por isso mesmo, ecoar sobre a pesquisa e as teorias científicas estrito senso - ao menos no caso da biologia, abrindo, porém, pela retomada e pelo prolongamento do sentido não explícito dos dados e progressos dos cientistas da evolução, a via de uma reflexão antropológica que se insere por seu próprio desenvolvimento no campo das ciências sociais que atravessam o século XX. Isso significa projetar uma biologia mais compreensiva, mais aderente a seus próprios dados e melhor preparada para assumir consequências de seus avanços, os quais indicam a continuidade entre os projetos do evolucionismo e as ciências sociais, num sentido bem diferente do que foi proposto, por vezes, pelo darwinismo reduzido.

A metafisica da vida oferece-nos ainda consequências relevantes para uma filosofia da natureza em sentido amplo, já que nela encontramos a determinação da unidade da natureza estabelecida no centro de A Evolução Criadora. O cerne dessa unidade dinâmica se encontra no âmago do livro; entretanto, e isso é fundamental, trata-se do mesmo tipo de unidade presente entre nossa dimensão animal e nossa humanidade - a continuidade que é inversão, modulação do nível de tensão, uma diferenciação do mesmo princípio que resulta na dupla forma do real assumida pela metafísica da duração. A cosmologia bergsoniana amplia o sentido de uma união anteriormente encontrada, ao mesmo tempo em que lhe fornece as explicações últimas. E, considerando-se que a vida, o bios, cujo movimento de conjunto resulta nas espécies e organismos, representa o compromisso entre o puro querer e a inércia material, cabe acrescentar que as teses maiores dessa cosmologia oferecem explicações mais férteis para os fatos evolutivos e, então, para a própria biologia. Esse retorno das consequências filosóficas sobre a ciência é, de resto, francamente assumido por ele, através de menções à convergência e mesmo coincidência entre filosofia e ciência na intuição, visão interior e observação exterior se recobrindo naquilo que constituiria o momento originário de uma ideia, hipótese ou visão efetiva e imediata de um objeto:

A ciência e a metafísica convergem, portanto, na intuição. Uma filosofia verdadeiramente intuitiva realizaria a união tão desejada entre a metafísica e a ciência. Ao mesmo tempo em que constituiria a metafísica como ciência positiva - progressiva e indefinidamente perfectível - levaria as ciências positivas propriamente ditas a tomar consciência de sen verdadeiro alcance, com frequência muito superior àquele que imaginam ter (BERGSON, 2009, p.41, grifos nossos). 
A 'união tão desejada' tem no corpus teórico da filosofia da duração ao menos um início de realização. As etapas em que se desenvolve o método da intuição, especificamente suas quatro obras maiores, arranjam-se de maneira semelhante no diálogo e na incorporação do trabalho da ciência. Se a descrição dos dados imediatos da consciência na sua primeira obra parte da crítica à psicologia científica e projeta um novo solo para uma psicologia mais fiel aos fenômenos dos quais tal ciência pretende dar conta, a recolocação do problema do dualismo em Matéria e Memória avança sobremaneira no que diz respeito à articulação entre problema metafísico e material empírico. Ali, Bergson por vezes faz desaparecer a linha demarcatória entre a descrição filosófica da consciência, da percepção e da memória e os paradigmas teóricos forjados no interior do trabalho dos cientistas. A solução para o problema do dualismo empreendida por essa obra constrói uma psicologia da memória que leva até o limite a diferença de natureza entre percepção e lembrança, para então encontrar numa configuração especial dos movimentos corporais a explicação psicológica fundamental que as correntes da tradição - realismo e idealismo na filosofia e o associacionismo reinante na psicologia científica do séc. XIX não puderam vislumbrar.

A resposta para uma filosofia do espírito consequente está na reelaboração teórica do papel do corpo, eis o pulo do gato da renovada filosofia de consciência oferecida por Bergson, uma psicologia (teoria do funcionamento do espírito que reelabora a análise do corpo próprio ou vivo) que preenche a lacuna responsável pelos artifícios teóricos do paralelismo e do epifenomenalismo, hipóteses pouco consistentes que atingem, por vezes, até mesmo o trabalho das neurociências contemporâneas ${ }^{5}$. Os resultados inovadores da ciência são ali mobilizados num papel essencial, o de 'desempate' entre hipóteses de âmbito metafísico (como a questão do desaparecimento, da localização e da recuperação das lembranças, conteúdo espiritual em convergência ou identidade, segundo os parâmetros adotados por tais hipóteses confrontadas, com a materialidade do cérebro ou do sistema nervoso) e recebem da teoria bergsoniana explicações mais condizentes com o sentido de seus dados. Confirmação de hipóteses e guias para a especulação filosófica, as pesquisas psicológicas e neurofisiológicas recebem também uma contribuição nada desprezível da teoria bergsoniana da memória e de sua solução para o problema do dualismo. Assim, Matéria e Memória tematiza pela

${ }^{5}$ Cabe sublinhar aqui que esse percurso dialoga diretamente com as pesquisas científicas sobre as afasias, em plena ebulição ao final do século XIX (trata-se do mesmo material empírico que está nas origens da psicanálise) e exibe pela primeira vez em contorno muito precisos a articulação ou união entre filosofia e ciência que é a chave da proposta de uma metafísica positiva tal como quer Bergson. 
primeira vez a tese de que uma ciência do espírito, ou moral, depende da reflexão de âmbito psicológico, cujo pressuposto de fundo é a biologia, ou a conformação biológica propriamente humana. Essa articulação preside o trabalho das duas obras seguintes, na medida em que é a noção de Vida que surge como essência da união entre alma e corpo, exigindo então o trabalho de A Evolução Criadora e semeando o solo da análise da moral e da religião no último livro.

Mas o biológico em Bergson não se separa do psicológico, uma vez que o trabalho da vida será aproximado ao da consciência. Isso significa que a construção de uma história individual em ato no mundo é o processo que explicita uma forma de existência mais vasta, precisamente o fundo a partir do qual a vida atravessa a matéria e, compondo com ela o amplo espectro de espécies e organismos que povoam a natureza, força a necessidade da extensão material e abre na natureza a fresta da indeterminação. Esse fundo, bem o sabemos, é a duração, compreendida como conjunto de virtualidades descrito à luz de uma totalidade, em construção ininterrupta, de lembranças próprias a uma vida singular. Eis o sentido da célebre afirmação de $A$ Evolução Criadora segundo a qual a vida é de essência psicológica. De resto, desde o início da elaboração de sua cosmologia, Bergson nos esclarece que se trata de perguntar se podemos atribuir à 'existência em geral' os mesmos predicados que foram encontrados no estudo da existência individual, ou seja, da vida consciente cuja excelência está na humanidade:

Buscamos apenas determinar o sentido preciso que nossa consciência dá à palavra 'existir' e descobrimos que, para um ser consciente, existir consiste em mudar, em amadurecer, amadurecer, em criar-se indefinidamente a si mesmo. Poder-se-ia dizer o mesmo da existência em geral? (BERGSON, 2005, p.8) ${ }^{6}$.

A filosofia moral de Bergson identifica-se em seus primeiros passos a um prolongamento da biologia compreensiva de $A$ Evolução Criadora, já que Duas Fontes é uma obra que toma como objeto de análise os processos essenciais à constituição da bumanidade enquanto espécie, dado o caráter especial do indivíduo que a constitui. A afirmação capital no início do livro não deixa nenhuma dúvida sobre esse ponto de partida: 'Atribuamos então ao termo biológico o

${ }^{6} \mathrm{~A}$ evolução da vida pensada à luz desse novo princípio, algo como a "Consciência em geral" condiciona a sua compreensão como movimento incessante no sentido da criação, e nos oferece, ao fim e ao cabo, os pressupostos para o mergulho nas consequências éticas de tal compreensão. A dualidade essencial da vida, que avança inevitavelmente marcada pela oscilação entre conservação e mudança justamente os atributos que o conceito-chave da filosofia bergsoniana, a duração, pretende conciliar reaparecerá então nos fenômenos da vida coletiva, isto é, sociais, morais e religiosos. 
sentido bem compreensivo que ele deveria ter, que tomará talvez um dia, e digamos para concluir que toda moral, pressão on aspiração, é de essência biológica' (BERGSON, 2008, p.60, grifos nossos). Para tanto, busca compreender como se articula uma relação entre todo e partes envolvendo indivíduos livres $e$ inteligentes que se associam de modo inelutável e inevitável para viver coletivamente segundo regras, costumes e representações fabuladas que funcionam como elos e fornecem a coesão necessária às sociedades. A vida social como organização desse coletivo sem o qual a espécie não vive, a religião como meio de afirmação da ligação entre os indivíduos que compõem os grupos, eis os fenômenos processuais que pertencem à essência do humano. Ao assim explicitar esse campo de fenômenos, isto é, como conjunto de determinações primordialmente necessárias à espécie, Bergson aponta qual é para ele o fundamento da sociabilidade, da moralidade e da religiosidade: esse fundamento é a vida. É a vida o horizonte último de compreensão e o campo originário (BOUANICHE, 2002, p.144.) das forças que dirigirão os fenômenos sociais, morais e religiosos. Essa origem única e una deriva, entretanto, em duas fontes distintas para os fatos a serem interpretados, e deparamos então com uma dualidade cuja unidade na vida precisa ser compreendida. Trata-se assim de encontrar os desdobramentos da filosofia da vida desenvolvida na obra anterior, bem como descobrir o ponto de tensão em que o social e o religioso se diferenciarão em natureza do biológico ${ }^{7}$. Sem entrar nos meandros deste ponto de tensão, nosso foco de análise se concentra aqui nas considerações que fomentam a continuidade entre a recolocação do problema da moral e a teoria da vida do livro anterior.

Num relance de olhos sobre as conclusões ali obtidas, exibe-se algo de essencial em meio ao conjunto de suas afirmações: a Vida, compreendida 'como uma vida de luta, e como uma exigência de invenção, como uma evolução criadora' (BERGSON, 2009, p.27, grifos nossos) identifica-se à própria realidade pensada à imagem de uma Consciência, tendência a criar que se detém provisoriamente diante da imobilidade que de si mesma ela se coloca como obstáculo, a matéria ${ }^{8}$. Consciência e materialidade, duas formas de existência 'radicalmente distintas' (BERGSON, 2009, p.18), compõem um amálgama em que a segunda, obstáculo criado pela simples inversão do ato essencial à primeira, é também o instrumento pelo qual o esforço criador é

\footnotetext{
7 Essa última questão não será objeto de nossas considerações aqui, pois ela só se compreende por uma leitura exaustiva de Duas Fontes que dê conta, inclusive, de todas as referências e reflexões sobre as ciências humanas e sobre o misticismo ali elaboradas,

8 Trata-se do centro do livro $A$ Evolução Criadora, passagem da análise biológica à intuição filosófica, que redunda na metafísica em que vida e matéria se apresentam como as forças em curso no real. A Vida, nessa medida, é a empresa do espírito, descrita como corrente de consciência.
} 
catalisado. Esse esforço engendra as espécies, nas quais as forças antagônicas se articularão compondo formas necessárias para que o impulso criador siga sua trajetória. O movimento de criação das espécies é compreendido, nesse contexto, como o meio de reconciliação entre a necessidade da matéria e a liberdade da consciência. Essa tese nuclear à metafísica bergsoniana é a razão última de uma dualidade concretamente vivida pelo homem, uma dentre essas várias espécies: a de procurar conservar-se a si e a seu modo de vida, em oposição à busca de transformação, avanço e criação. Se a vida propriamente humana é mistura, oscilação e até conflito entre essas duas presenças, cabe levar a reflexão que pretende compreendê-la absolutamente aos 'dois limites teóricos puros, inscrevendo a humanidade entre dois movimentos, um de enraizamento na natureza, outro de superação e de progresso que abre o humano a uma história' (BOUANICHE, 2002, p.144).

A moral fechada, constituída naturalmente em benefício da espécie humana, e sua abertura à sociedade dos homens (conduzida por potencialidades individuais próprias aos componentes dessa espécie, privilegiados por sua inteligência e sua liberdade), a religião estática engendrada como proteção da espécie contra os perigos que as idiossincrasias de seus componentes podem produzir por sua capacidade intelectual, e sua potencial passagem a uma religião dinâmica de base mística, eis os pares que se trata de diferenciar e em relação aos quais, através da reinterpretação do material empírico oferecido pelas ciências sociais, encontrar linhas de fato para ascender ao seu ponto de convergência. De onde a necessidade de retomar a noçãochave cujo papel se desvelou na metafísica da vida: a humanidade. As aquisições de $A$ Evolução Criadora necessitam, e isto é essencial, do estudo da vida moral e religiosa como complemento indispensável a uma teoria do homem - e isto para além de exigirem o trajeto de Duas Fontes por razões de ordem metafísica nas quais residem as finalidades mais radicais da filosofia da duração. Bergson nos oferece em seu estudo da vida argumentos elaborados (e fundados no centro empírico do livro, a teoria biológica da evolução) para mostrar como esse apelo e essa dimensão de complementaridade articulam uma tese decisiva do ponto de vista antropológico, a de que a relação especial entre espécie e indivíduos condiciona uma filosofia moral e uma concepção sobre as formas de religiosidade. Para além disso, tais argumentos trazem ao bojo da sua filosofia uma nova dualidade de base que vem recobrir outros pares de tendências analisados, dissociados e unificados em seus princípios ao longo de todas as obras do filósofo.

Tentemos explicitar melhor a delimitação dos novos pares. As oposições entre moral fechada e moral aberta e entre religião estática e religião dinâmica encontram sua explicação através da retomada da gênese da 
humanidade enquanto tendência específica da animalidade, aquela cujos indivíduos se estruturam em torno de um sistema nervoso altamente evoluído que funciona como base da inteligência, faculdade que resulta, por seu lado, de uma exteriorização da consciência modelando-se pela matéria bruta. Essa tonalidade da duração, o humano, que concentra alto grau de liberdade, precisamente por ser capaz de um domínio ímpar da matéria e de uma imensurável invenção de ferramentas, configura um indivíduo livre e criador, cuja sobrevivência, entretanto, está fundada no seu pertencimento à espécie na medida simplesmente em que se trata de um ser vivo, um bios. Ao desvendar a origem da sociedade no movimento vital, Bergson reencontrará a dupla dimensão da vida, criação e conservação, agora redimensionada nos processos de organização da existência humana, e por isso a oposição reinstalada terá, de imediato, consequências éticas. Uma das inúmeras passagens em que o filósofo formula a oposição é aqui paradigmática: o estudo da sociabilidade revela dois tipos de moralidade que ora são referidos como formas distintas e independentes, ora como duas metades de uma e mesma moralidade e que correspondem a grupos sociais diferentes em natureza, dois tipos de totalidades - a 'cidade' e a humanidade inteira, a primeira necessariamente limitada e referida a um 'inimigo' (ou seja, presidida por um fator externo que dirige sua inclinação à vida coletiva), a outra ilimitada e impelida pelo amor ao humano em si mesmo, impulsionada pela emoção criadora e incitada por indivíduos privilegiados e excepcionais (aos quais Bergson se refere por vezes através do termo heróis). A passagem paradigmática refere-se a essa diferença através do vocabulário do movimento:

'Entre a primeira moral e a segunda há então toda a distância do repouso ao
movimento, A primeira é suposta imutável, Se ela muda, ela rapidamente se
esquece de que mudou ou não afirma o movimento. A forma que ela apresenta
em não importa qual momento pretende ser a forma definitiva. Mas a outra é
um impulso, uma exigência de movimento; ela é mobilidade em princípio
(BERGSON, 2008, p.56)

Mencionamos acima que a corrente de vida produz as espécies por diferenciação e dissociação de uma totalidade plena de tendências imbricadas, e a origem comum no elã de vida pode dar conta da relação de harmonia dissonante ou divergência complementar que a ciência constata na distribuição das espécies vivas. No caso do homem, sua origem na animalidade especializa a via

\footnotetext{
${ }^{9} \mathrm{~A}$ moral fechada vem assim recobrir a inversão da tensão ou do movimento próprios à duração, isto é, a instauração ontológica da tendência à distensão pela gênese da matéria, inversão e gênese que se acentuam através do conhecimento intelectual que se modela pela "ex-tensão" de comportamento inercial e a conceitua como imobilidade. Sobre isso ver $A$ Evolução Criadora, capítulo III, particularmente o movimento de texto em que Bergson efetua a gênese concomitante da materialidade e da inteligência.
} 
intelectual, e como ser cuja essência é a inteligência ele constituirá sociedades ao atualizar essa virtualidade mesma. Como espécie inteligente, a humanidade é socializada em sua origem, eis uma das principais aquisições do trajeto de $A$ Evolução Criadora. Bergson descreve a história evolutiva como movimento de dissociação de uma corrente imbricada de virtualidades em tendências divergentes e complementares e atinge afirmação filosófica capital ao livro, a de que a vida se comporta como uma Consciência originária cuja intenção é avançar livremente. $\mathrm{O}$ avanço da vida, entretanto, exige e depende das paradas pontuais que constituem as espécies enquanto tais. A espécie humana, por sua constituição própria (por sua inteligência) trará inscrita em si a contraposição entre o avanço do elã no sentido da criação e da liberdade, e a necessidade da espécie de conservar-se no tecido da natureza e em luta contra os obstáculos naturais. A vida coletiva e social, baseada numa moralidade que lhe serve de liga, é a forma pela qual a Vida possibilita a sobrevivência; no caso das sociedades de insetos, é a tendência que define tais espécies que responde pela sobrevivência, ou seja, o instinto enquanto prolongamento do trabalho da própria vida. Eis a tensão imanente às sociedades humanas, presente desde as primeiras linhas do trajeto de Duas Fontes.

Ainda uma observação sobre a continuidade do trajeto do livro deve ser mencionada. Se a vida em sociedade desenvolve-se a partir de duas fontes, a sua unidade de princípio (que remonta à duração como estofo do real) sustentará a tese de que ao homem é possível a superação da naturalidade da espécie por uma via cultural que faz da sua história algo de qualitativamente distinto da história natural da animalidade. Os fenômenos tomados como foco da investigação, a despeito de que sua análise levará até o limite a diferença entre as duas tendências atuantes na constituição da vida social, revelarão que a reversão necessária para garantir a completude entre as tendências tem seu agente no indivíduo. Entrarão em cena assim as singularidades excepcionais que conhecem a vida de dentro, interiormente, por uma experiência psicológica particular, e agem como modelo para os outros, expressando exteriormente aquilo que de algum modo experimentaram. Isso significa que, e eis o ponto de torsão próprio ao estudo das sociedades, tal prolongamento do estudo da espécie humana (cujos momentos mais decisivos se encontram em $A$ Evolução Criadora) reverte de certo modo a origem vital do humano em favor dos indivíduos, na medida em que inteligência e liberdade se manifestarão de maneira peculiar e excepcional em singularidades realizando de fato aquilo que de direito está implicado na linhagem evolutiva da inteligência: o apelo ao respeito de toda a humanidade e a aspiração ao amor que a moral aberta e a religião dinâmica implicam. É nessa preponderância do papel do indivíduo que reside o ponto 
de distanciamento entre a 'dupla dualidade' que se trata de elucidar ${ }^{10}$. Mas a superação do meramente biológico em favor da moral aberta e da religiosidade dinâmica só pode ser explicada pela incorporação do material das ciências com as quais o aprofundamento da investigação de Duas Fontes contará.

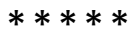

O problema investigado por Bergson em Duas Fontes, uma vez que se concentra sobre a relação entre o social e o individual, defendendo a imanência da sociedade aos indivíduos inteligentes (isto é, aos seres humanos tal qual a natureza os constituiu), enfrenta nessa medida um debate clássico no âmbito da sociologia. Assim como ocorre na história das ciências sociais, cabe posicionar-se sobre o lugar de investigação próprio a esse debate, e ao referir a fonte da sociabilidade à vida, articulando sua própria concepção biológica à análise da obrigação moral e das representações religiosas, Bergson define esse lugar de maneira muito convergente com a antropologia. Essa posição é defendida por Keck, para quem Duas Fontes, ainda que firme seus primeiros passos por meio de uma retomada de teses defendidas pela sociologia de Durkheim, ao fazer a crítica e indicar o ponto de divergência com tal escola, acaba por eleger a antropologia como foco privilegiado de confronto e conformação, por meio do uso de seus dados e da construção de hipóteses sobre a humanidade enquanto tal. Seu debate e sua reapropriação do material empírico dirigem-se assim, muito mais do que às correntes sociológicas, a esta

ciência que, desde Comte a Lévi-Strauss tomou o nome de antropologia e da qual o homem é a uma só vez sujeito e objeto, que coloca o problema da humanidade, isto é, o problema que coloca para a vida esta espécie particular que é a humanidade, espécie definida pela inteligência e pela liberdade, e em contrapartida, o problema que se põe para o homem o fato de ser uma espécie viva, tendo lugar numa evolução biológica cujo movimento ela prolonga (KECK, 2002, p.197) ${ }^{11}$.

\footnotetext{
10 Por que falamos numa dualidade que é "dupla"? Precisamente porque ela envolve duas dimensões da vida humana complementares, moral e religião: entre uma coletividade organizada segundo hábitos e obrigações e uma totalidade inspirada pelo amor à humanidade, reside a distância entre 0 aberto e 0 fechado; entre uma religião referida a um grupo que nela se reconhece e cujo modelo mais fundamental é o totemismo, e um religião fundada individualmente pelo retorno à duração, de base mística, está a diferença entre o estático e dinâmico. As duas oposições se inter-relacionam e não têm referência direta a um tipo de sociedade localizado no tempo e no espaço em oposição a outro, nem a uma forma de religião definida historicamente.

11 Citamos o texto aqui tomado como fonte preciosa de indicações, na medida em que defende e esclarece o uso específico dos fatos positivos sobre os quais repousa o trabalho das ciências sociais, permitindo comparar a apropriação de tais fatos com as relações estabelecidas por Bergson com a psicologia e a biologia nos livros anteriores. Se há diferenças bem relevantes entre os livros, referidas às ciências que neles são discutidas, Keck tem o mérito de mostrar que também em Duas Fontes a análise filosófica não se faz sem o confronto da intuição com "uma ciência que fornece os fatos positivos nos
} 
Keck também aponta como a relação com as ciências sociais pode iluminar o procedimento próprio ao filósofo da duração ao descrever a sociedade humana e seu comportamento religioso, no primitivo e no civilizado, por sua origem biológica. Mas trata-se do biológico no sentido especial de processo de criação próprio ao movimento do elã vital: a implicação social no vital, que reporta as descrições de Duas Fontes ao percurso de $A$ Evolução Criadora, significa em última análise buscar 'no vital o aquém do social'; mas a tese de que as criações singulares de indivíduos que revertem o caráter fechado da sociedade naturalmente instituída e engendram a retomada do movimento criador, concomitante à consciência de si como espécie, aponta uma dimensão própria e apenas possível para o ser humano. Nesse sentido, o alvo final da passagem do fechado ao aberto, por conta das possibilidades de libertação e superação de si próprias apenas a um grupo de seres vivos, consiste na humanidade enquanto tal, e 'o retorno à biologia a partir da sociologia é então a condição de uma superação da sociologia pela antropologia' (id. p.190). O contexto do livro, enriquecido por essas observações, ganha um novo contorno: trata-se de pensar a humanidade enquanto tal e suas possibilidades de superação da condição natural, e a dualidade problematizada (desde o título cuja impressão no leitor é no mínimo intrigante) ao longo da obra traz consigo uma implicação essencial ao século $\mathrm{XX}$, a de que ela recobre, em diversos niveis de análise, a relação entre naturez̧a e cultura, cujas nuances delimitam propostas diversas na antropologia.

Mas como se estrutura a investigação que tomará sociologia e antropologia como contraponto e material empírico, assim como ocorreu com a psicologia e a biologia nas obras anteriores? Há sempre, na trajetória investigativa de Bergson, um trabalho teórico preparatório que condiciona o diálogo com as ciências. Agora, em Duas Fontes, esse trabalho surge já bem enriquecido das soluções teóricas desenvolvidas a partir dos problemas sobre os quais o filósofo se debruçou: a liberdade e a teoria das multiplicidades que a fundamenta; a união entre espírito e matéria através da psicologia da memória e a metafísica da vida calcada na reinterpretação do evolucionismo - estarão todos, de alguma maneira, implicados na configuração inicial do problema da moral e da religião. Examinemos, então, uma das variáveis que operam em tal configuração, a noção-chave para dar conta da moralidade da espécie e a consequente oposição entre fechado e aberto - o todo da obrigação.

Vejamos aquilo que se apresenta como peculiar às configurações da vida humana descritas na obra As Duas Fontes da Moral e da Religião através,

quais ela pode se provar e com um problema que apresente tais fatos num tal arranjo que eles demandam um tratamento filosófico". 
sobretudo, da oposição entre o aberto e o fechado. Recortamos assim um momento preciso da obra, que de resto tem uma amplitude monumental ${ }^{12}$ : a descrição da moralidade cujo fio condutor é noção de todo da obrigação, atravessando o primeiro capítulo, em que a contraposição entre sociedades fechadas e almas abertas é determinada, buscando ali esclarecer o papel da noção de hábito como intermediário entre a inteligência e o instinto (uma pouco adiante avançaremos algumas considerações sobre esse papel). Cabe observar aqui, apenas a título introdutório, que a essa dimensão da vida em sociedade, Bergson acrescenta um estudo profundo e original sobre os mecanismos de constituição da religião, delineando os traços essenciais de uma religiosidade estática, especialmente através da noção de 'função fabuladora' da inteligência (e seu complemento, o 'senso social') nela enfatizando o papel da tese sobre o funcionamento da criação de representações supersticiosas fundadas num instinto virtual - a resposta de Bergson ao problema da irracionalidade imanente aos seres dotados de inteligência que sustenta a afirmação radical de que é preciso dar conta do fato de que nunca houve sociedade sem religião ${ }^{13}$. A indicação de uma função específica derivada da inteligência para defender o homem de suas próprias representações, a fabulação, está entre as mais férteis contribuições do filósofo para o estudo dos mitos, fábulas, superstições e assim da produção cultural em geral, introduzindo a filosofia da duração no campo de estudos das sociedades primitivas, da história e da antropologia. A tese original de que essa função fabuladora vem atuar instintivamente e interferir na capacidade de representar, atendendo à necessidade de defesa contra um poder próprio de dissolução e depressão do humano atribuído à intelectualidade, é apontada por vários estudiosos de Duas Fontes como núcleo da filosofia bergsoniana da religião. Desse modo, as relações entre essa nova teoria da religião, inseparável de sua filosofia moral, com a produção teórica em torno do tema no início do século

\footnotetext{
12 Este livro, além de retomar várias conclusões da obra inteira de Bergson, em razão de seu próprio tema apresenta uma riqueza de referências a autores das ciências sociais, à filosofia moral kantiana e à história das religiões, configurando assim material para diversos tipos de pesquisa e mesmo, em se tratando de filosofia, para variados escopos de problemas filosóficos.

${ }^{13}$ Trata-se de parte substancial do segundo capítulo, A Religião Estática, e sua surpreendente retomada da formação de ideias ou produção de representações, concentrando-se agora naquelas que se originam do medo e funcionam como proteção à espécie, percurso no qual Bergson elege Lévi-Bruhl, outro teórico da antropologia, como interlocutor. Com efeito, Bergson inicia seu estudo sobre a religião apontando 0 absurdo no seio da racionalidade: as religiões primitivas humilham a inteligência, por serem tecidas de "aberrações". Chama atenção, para além do fato de prescreverem imoralidades e até crimes, o fato de que as superstições aparecem em todas as sociedades, ou antes, "a superstição mais baixa foi, por longo tempo, um fato universal... Não houve jamais sociedade sem religião" (BERGSON, 2008, p.105). Nada no comportamento animal exibe sinais de religiosidade, então o homo sapiens, "único ser dotado de razão, é único também que pode suspender sua existência a coisas irracionais" (id.).
} 
XX exige um acompanhamento em detalhe da construção dessa tese, buscando elucidar como é 'a partir da natureza que Bergson deduz as funções da religião, incluindo a própria existência da mesma' (FRANÇOIS, 2008, p.125) ${ }^{14}$. Nossa intenção, ainda que não se trate desse ponto aqui, é a de que o esclarecimento da base da análise da moral possa servir efetivamente para esse trabalho posterior. Além disso, é no percurso do segundo capítulo, ao descrever a gênese da religião, que Bergson oferece as contribuições mais relevantes ao debate antropológico do século XX, o que foi reconhecido por Lévi-Strauss ao retomar as análises do totemismo em Duas Fontes mostrando precisamente nelas a via situada entre 'as hipóteses extremas de Lévi-Bruhl e Durkheim' (LÉVI-STRAUSS, 1986, p.119) ${ }^{15}$.

A delimitação do problema da moral por Bergson parte, como dissemos anteriormente, da análise da teoria da vida e especialmente da objetividade pela qual Bergson funda sua tese de que a vida se efetiva como uma consciência que aspira à liberdade. Dessa tese depende a descrição do movimento dissociativo da evolução vital, o qual condiciona por sua vez a compreensão das tendências organizadas pela ênfase no instinto e sua relação de divergência complementar com as de índole intelectual. Mas, mesmo reconhecendo a rearticulação entre inteligência e instinto - através da consideração do hábito na coesão social e da função representativa que busca proteger instintivamente a espécie de perigos produzidos pela própria inteligência - como fundamento mais importante das descrições sobre a moral fechada e a religião estática, consideramos que o percurso de diálogo com o material das ciências sociais e o compartilhamento de objetivos com a antropologia inscrevem a análise de Duas Fontes numa trilha que permite um passo a mais em relação à biologia compreensiva da obra anterior. Mais precisamente, a relação com as ciências sociais e a consideração de dimensões humanas cujas expressões nos indivíduos configuram ações e representações originais em relação à espécie são dois fatores fundamentais ao papel de Duas Fontes como chave de compreensão última da realidade como duração, portanto, da metafísica. Da duração da consciência à apreensão dos 'princípios últimos do real', a articulação entre psicologia, biologia e antropologia apresenta-se como núcleo

$14 \mathrm{O}$ texto de Arnaud François, bastante elucidativo, remete a teoria bergsoniana ao diálogo com outros autores, particularmente Nietzsche. Ver FRANÇOIS, 2008, p.121 a 136.

15 Lévi-Strauss dedicou o capítulo final de 0 Totemismo Hoje a Bergson, valorizando sua capacidade (que 0 autor aproxima da de Rousseau) de conhecimento dos fenômenos antropológicos de dentro: "experimentando neles próprios modos de pensamento antes apreendidos de fora, ou imaginados" (LÉVI-STRAUSS,1986, p.131). O que indicamos aqui é justamente como a abertura de Duas Fontes condiciona o tipo de relação entre filosofia e antropologia que pode ser apontado como significativo legado de Bergson para as ciências humanas. As menções de Lévi-Strauss a Bergson podem, portanto, receber esclarecimentos produtivos e a atenção devida dada sua fertilidade. 
de uma metafísica renovada. O seguinte comentário sobre esse papel de Duas Fontes é pleno de indicações:

\begin{abstract}
Ao considerar o fato empírico da evolução, Bergson constatou, na raiz do real, um processo primitivo de criação análogo a uma consciência que dura. Tudo se passa presentemente como se, ao concentrar sua atenção sobre a 'ponta' dessa evolução, sobre a vida 'humana', Bergson descobrisse as mais altas manifestações de criação, capazes de levá-lo ainda mais longe em sua elucidação do princípio da realidade (BOUANICHE, 2004, p.41, grifos nossos).
\end{abstract}

A remissão da dualidade de fontes da moral e da religião à vida como fundamento e princípio é ponto pacífico entre os comentadores de Duas Fontes $^{16}$. O que se modifica é a interpretação do modo pelo qual Bergson funda essa referência, bem como do caráter especial próprio às etapas de análise que ele percorre. Consideramos que a principal noção que opera no primeiro capítulo da obra, o todo da obrigação, deve ser explorada em profundidade, na medida em que ela preside os primeiros confrontos com autores como Durkheim e Kant, fazendo emergir os avanços teóricos propriamente bergsonianos. Como manifestação da vida, a coletividade institui de si uma pressão advinda da sintese dos hábitos que se desenvolvem socialmente, e ao assim definir a fonte da moralidade da espécie, Bergson já se afasta da 'noção de obrigação presente na sociologia de Durkheim, necessariamente exterior ao que determina' (TEIXEIRA, 2014, p.361) ${ }^{17}$. Em se tratando de uma síntese de hábitos, como analisaremos mais adiante, retoma-se o corpo próprio e a memória que o caracteriza, tal como as análises de Matéria e Memória estabeleceram.

Avançamos aqui que se trata, portanto, de enfatizar o papel da noção de memória, a mesma que responde pela consideração do elã vital como totalidade originária de tendências imbricadas (a segunda de suas

\footnotetext{
${ }^{16}$ Assim, a unidade sob a dualidade atravessa o trajeto do livro e ganha contornos próprios, que serão 0 alvo dos comentários mais relevantes a esse trajeto, a maior parte deles convergentes com a observação precisa de Worms: "a tese principal de Bergson nesse livro é mesmo a seguinte: o que funda a moral e a religião, sob sua forma tanto fechada quanto aberta, não é nem a razão, nem a sociedade, nem qualquer outra coisa de absolutamente transcendente, mais é a vida" (WORMS, 2004, p.269). Cabe lembrar 0 aporte crítico dessa tese de fundo: nem a sociologia de Durkheim, para quem a moral se funda em absoluto na sociedade (para além da qual nada há a procurar), nem a filosofia prática de Kant, calcada na razão como fundamento, souberam dar conta dos fenômenos em questão: ambos negligenciaram o que acaba por condicionar inclusive os argumentos, motivos e razões, numa palavra, 0 trabalho da inteligência, na justificativa da obrigação e o dever cujo valor, fundamento e significação residem no vital.

17 No caso de Durkheim, o diálogo estabelecido contrapõe a pressão da obrigação como interna à sociedade humana, que se deixa levar pela naturalidade de sua vida social e da pressão que dela emana, e a "transcendência que distingue o social durkheiminano" (TEIXEIRA, 2014, p.361) definido por uma coação exterior. A interioridade da pressão defendida por Bergson depende, eis o nosso ponto aqui, da raiz corporal e vital dos hábitos coletivos.
} 
caracterizações essenciais, complementar à sua dimensão de impulso ou movimento incessante), na conformação de tal noção, pois a originalidade de Bergson reside em mostrar, na fonte da moralidade e da religiosidade, o papel do hábito e do instinto. Nesse contexto, ao partir da tese de que a vida em evolução progride ao modo de uma consciência, é como memória que se compreende os restos de instinto na intelectualidade (e vice-versa), tese sem a qual o autor não pode dar conta de um conjunto de hábitos advindos da educação e da vida coletiva que, enquanto totalidade imanente à suas partes, implica uma coesão que imita ou se aproxima do instinto reinante nas comunidades de insetos como as abelhas e as formigas. Trata-se da referência capital do primeiro capítulo de Duas Fontes à ideia de instinto virtual, resultante, por sua vez, da afirmação de que o conjunto de hábitos coletivamente instituídos é incorporado pelos indivíduos de modo que possam assentir a essa totalidade ao simplesmente seguirem suas prerrogativas vitais, já socializadas como condição de possibilidade da sobrevivência da espécie.

Além disso, se entendemos que somente através da articulação entre vida e consciência é possível seguir Bergson em sua definição da sociedade humana tal como a natureza a condiciona - assim como entender em que medida existe, nessa sociedade 'natural', a potencialidade de superação da moralidade da obrigação e do dever que a sustenta - é indispensável fazer interferir nesse trajeto a descrição da consciência como memória. Com efeito, o elã vital é memória, uma vez que Bergson compreende o movimento dissociativo da vida em reinos e espécies como desdobramento de tendências que são unidas em sua origem, carregando consigo a 'lembrança' dessa unidade originária. A presença da identidade comum em linhagens distintas no movimento evolutivo é um dos principais argumentos utilizados para denunciar as lacunas dos teóricos do transformismo, sobretudo sua incapacidade de explicar as homologias estruturais em espécies muito distantes no tempo e no espaço, justamente porque não souberam compreender a harmonia do mundo organizado:

\footnotetext{
A harmonia não existe então de fato, mas antes de direito; eu quero dizer que o elã original é um elã comum e que, quanto mais remontamos ao alto, mais as tendências diversas aparecem como complementares umas às outras. A harmonia se revela nas tendências e, eis o ponto sobre o qual o finalismo se enganou gravemente, a harmonia se encontra antes atrás do que na frente. Ela se deve a uma identidade de impulsão e não a uma aspiração comum. É em vão que se quer atribuir à vida um objetivo, um fim no sentido humano do termo (BERGSON, 2005, p.55, grifos nossos).
}

Como memória da impulsão inicial, as tendências carregarão em si algo das outras, daquelas em relação às quais se dissociaram. Essa tese central, de resto fundada no acompanhamento minucioso das linhas de fatos, mostra 
como a implicação entre vida e consciência exige que se compreenda a evolução das espécies como a articulação entre um passado comum e um porvir indeterminado. As páginas iniciais de Duas Fontes, ao tratarem do todo da obrigação que responde pela coesão social, retomam a relação entre instinto e inteligência precisamente determinada por Bergson à luz dessa interpretação temporal do vital. E as sociedades organizadas pelas tendências da espécie humana, definidas essencialmente pelo estabelecimento de fronteiras entre grupos que se tomam como antagonistas (e cuja derivação quase inevitável é a guerra), são estruturadas através de uma moralidade que atua por pressão, forçando seres inteligentes a se unirem tal como células num organismo. A obrigação e o dever são então constituintes, estruturantes, e respondem por sua coesão e manutenção. Mas é precisamente nessa constituição, que envolve indivíduos inteligentes e livres numa coletividade que se comporta à maneira de um instinto, que estão presentes virtualmente as condições de abertura ao todo da humanidade, marca de uma sociedade aberta ou antes daquilo que de sociedade passa à humanidade como valor e ideal. A moralidade de apelo ou aspiração surge então no percurso analítico como segunda metade da moral do dever e significando a completude da mesma. Memória, hábito e instinto serão responsáveis, através de sua modulação via inteligência, pela passagem do fechado ao aberto ou ao menos pelas condições de possibilidade dessa transição. E sua investigação na composição da moralidade e da religiosidade vem esclarecer, é o que assumimos a título de hipótese, como natureza e cultura se articulam no desenvolvimento progressivo da bumanidade.

Qual é o papel desempenhado pela noção de hábito na definição bergsoniana da moralidade cuja fonte é a pressão da obrigação? A presença da memória motora, raiz última de todo hábito - sem que ainda analisemos qual é a diferença entre a dimensão motora e a dimensão social na aquisição de repertórios adaptativos como mecanismos habituais - no trajeto do primeiro capítulo de Duas Fontes evidencia seu papel estruturante na coesão social. Por essa tese, Bergson mobiliza algumas de suas mais férteis aquisições advindas do estudo dos processos conscientes, em especial o papel da memória em sua dupla dimensão, motora e representativa, na análise psicológica, definida como 'estudo do espírito funcionando utilmente para a prática' (BERGSON, 1999, p.9) na abertura de Matéria e Memória. Lembremos de que o livro, inteiramente dedicado ao problema do dualismo, pode ser considerado como núcleo irradiador para todos os pares de oposição que se configuram como objetos de investigação nas outras obras, incluindo esse de que nos ocupamos aqui. Além dessa dimensão especial da psicologia da memória, é importante ainda ressaltar que o livro acaba por esclarecer, no nível das ações e do conhecimento humano, como o 'espírito empresta da matéria as percepções de onde se nutre, 
e lhe devolve sob a forma de movimento, no qual ele imprimiu sua liberdade' (BERGSON, 1999, p.291) ${ }^{18}$.

É nesse contexto que encontramos a raiz da noção de hábito, primeiramente no hábito corporal, descrito e fundado como uma memória. Ocorre que, mais do que uma organização de movimentos que se adquire por repetição e imitação, esforço de aprendizagem guiado pela imagem difusa do movimento observado no outro, o hábito é também o que define a base de um organismo vivo, em seus processos de ação no mundo em que objetos são incorporados e reações apropriadas são montadas como mecanismos motores. Para Bergson, essa capacidade reconhecida como memória motora é então o fundamento da adaptação, e tudo o mais que se segue na práxis humana, a formação de ideias, o uso da linguagem e as produções culturais dependem em alguma medida da organização de mecanismos nucleados pelo sistema nervoso. Assim, uma vez que a sociabilidade é um dos pilares da conservação da humanidade como espécie, e o seu corpus contém uma série de hábitos aos quais assentimos quase que automaticamente, a coesão social está fundada nos mesmos processos que respondem de modo mais amplo pela organização do corpo situado no mundo. A aprendizagem de um exercício físico ou de um passo de dança exige a intervenção de uma inteligência corporal, na medida em que o corpo compreende um movimento quando é capaz de reproduzi-lo ativamente. Ora, essa capacidade reprodutiva se efetiva quando os movimentos articulados num mecanismo se unem de maneira que o todo formado não é mais uma justaposição de etapas ou partes, mas sim uma totalidade virtual imanente a suas partes que chamam umas às outras, no momento de sua atualização, como se dá com as notas de uma melodia. Em uma palavra, o hábito, uma das resultantes dessa aprendizagem, situa-se no meio do caminho entre o automatismo e a organicidade da duração. Ele resulta da memória corporal que nos propicia o reconhecimento praticamente dado no corpo, quase instantâneo, advindo da 'consciência de um acompanhamento

18 Trata-se da última frase de Matéria e Memória, e sintetiza a primeira descrição da inserção de liberdade no mundo, no universo material mais precisamente, pelo espírito humano tomado nas démarches individuais. Num certo sentido, essa inserção de liberdade na materialidade é o que $A$ Evolução Criadora tratará de explicar em nível cosmológico. Essa relação, entre os processos conscientes que indeterminam as ações no mundo, e o processo evolutivo como luta da vida para avançar atravessando a materialidade e com ela constituindo as espécies, expressa como a psicologia é o foco irradiador para a biologia, e agora vemos em Duas Fontes como a biologia é o foco irradiador para a moral, a religião e assim para a libertação efetiva do homem. Considerando que a psicologia compreensiva de Matéria e Memória é uma psicologia essencialmente centrada na memória, percebemos como a tese de que a "consciência significa primeiramente memória" (BERGSON, 2009, p.5) recebe um significado mais profundo do que normalmente se considera no campo dos estudos bergsonianos. 
motor bem regulado, fundamento do sentimento de familiaridade' (BERGSON, 1999, p.104) que nos toma uma vez iniciados esses mecanismos, dada a sua organização: 'o hábito de usar um objeto acabou portanto por organizar ao mesmo tempo movimentos e percepções, e a consciência desses movimentos nascentes estaria aqui na base do reconhecimento' (BERGSON, 1999, p.105).

Resta perguntar se os hábitos sociais compartilham desses mesmos predicados, referidos, não custa repetir, à organização própria ao corpo vivo. Sem adentrar nesse ponto, podemos enfatizar que o estudo dessa síntese de hábitos coletivos começa por essa questão. Mas uma consequência capital surge aqui: se Bergson pode conferir ao conjunto de hábitos adquiridos na vida intersubjetiva ou coletiva a organicidade própria às comunidades de base instintiva, essa totalidade estará incorporada aos indivíduos por sua dimensão prática e vital, influindo sobre eles não mais como força exterior (e aqui está o ponto de divergência com a sociologia de Durkheim), mas como pressão interior. Essa inversão em relação ao fundamento, ou melhor, à fonte do dever será o fundo teórico à luz do qual Bergson poderá, pelo diálogo com as ciências, avançar na determinação da diferença entre o hábito motor e o hábito propriamente social. O ponto que desejamos frisar é exatamente esse: se Bergson preparou as condições de possibilidade para uma filosofia da sociologia, da antropologia ou da moral, o campo de tais condições é delimitado por essa noção, e é a partir dela que se pode compreender as críticas, a aceitação parcial e o trabalho de extração de lições filosóficas a partir do confronto com a história do pensamento social anterior e contemporâneo a Bergson. Esse trabalho inicial converge, assim, com os mesmos passos efetivados nas outras obras como preparação para o diálogo com a ciência, a teoria da percepção pura no caso da psicologia e da neurofisiologia, a imagem do elã vital no caso da biologia evolutiva.

A relação entre o hábito e a totalidade orgânica ou espiritual permite assim compreender porque o todo da obrigação se aproxima da noção de instinto, na medida em que Bergson frisa ao menos o valor teórico dessa analogia. A coesão do todo da obrigação se comporta como se fosse a coesão do instinto no trabalho próprio a uma colmeia de abelhas. Essa aproximação exige um novo passo para a análise da moral e da religião, e que consiste numa das principais teses do livro inteiro: conferir fundamento à afirmação de que seres dotados de inteligência (como ferramenta que os define enquanto espécie) podem, pelo uso mesmo dessa faculdade, imprimir em seu comportamento as características próprias ao instinto. Trata-se de mobilizar nesse contexto a descrição bergsoniana do instinto em $A$ Evolução Criadora. Com efeito, o trajeto que explicita as tendências nas quais a vida se dissocia em 
seu progresso evolutivo encontra seu ápice na explicação da origem comum e na divergência de funcionamento entre instinto e inteligência. O retorno parcial ou virtual à tendência do instinto numa coletividade de seres definidos por sua inteligência - ou antes, por seres que configuram a espécie em que a inteligência se acentuou e tornou-se dominante, sem que isso signifique a extinção pura e simples das determinações instintivas, sempre segundo as conclusões da teoria da vida - se apresenta ali como base da coesão social. E o hábito social, que responde pelo assentimento ao todo da obrigação, será descrito como a mediação da inteligência para a composição de um organismo virtual, que funciona virtualmente como o instinto. $\mathrm{O}$ trajeto de análise da ordem social nos mostra, passo a passo e em constante referência à analogia com o organismo composto de células, que a moral fechada é imanente à sociedade humana, além de ter como fundamento uma totalidade coesa de costumes, hábitos e regras às quais assentimos quase que automaticamente justamente o todo da obrigação. Ela representa assim uma fonte especial de estruturação, de formação de um sistema:

\begin{abstract}
'a pressão que os elementos da sociedade exercem uns sobre os outros para manter a forma do todo, pressão cujo efeito é prefigurado em cada um de nós por um sistema de hábitos que vão por assim dizer para além dela: esse mecanismo, do qual cada peça é um hábito, mas cujo conjunto é comparável a um instinto, foi preparado pela natureza' (BERGSON, 2008, p.53).
\end{abstract}

Esse ‘mecanismo' é o todo da obrigação, síntese dos hábitos cuja força adquirida não se compreende como soma da força de cada um desses hábitos particulares - o todo aqui é mais que a soma das partes, configura-se como qualitativamente distinto deles. Se esse conjunto especial sobre o qual se assenta a obediência como cumprimento do dever é comparável ao instinto, isso significa que ele se comporta como um mecanismo que prolonga a ação da vida como criadora das espécies, mecanismo inato a essas espécies criadas que não faz senão prolongar o trabalho da vida. É pela análise em detalhe do modo pelo qual o instinto prolonga o trabalho em espécies determinadas, e cuja marca Bergson define como a simpatia, que a coesão social se esclarece em sua raiz eminentemente vital. Aprofundando tal relação, o todo da obrigação exibe toda a sua riqueza enquanto, segundo as palavras de Keck, solução bergsoniana para uma das questões desde sempre enfrentada pela antropologia, a saber: como se dá a articulação entre as representações individuais e as coletivas na coesão das sociedades. Para o autor, Bergson evita o dualismo por essa descrição que é de alguma forma estrutural: 'cada comportamento individual é concebido como uma posição num todo necessário que só tem existência virtual e cuja origem é biológica' (KECK, 2002, p.202). O problema do instinto se apresenta, portanto, com 
surpreendente força na investigação da moral, dado que o comportamento da sociedade em sua figura naturalizada, ou seja, em sua dimensão de fechamento, se explica como recurso aos restos de instinto numa espécie cuja tendência essencial, a inteligência, traria dificuldades e mesmo perigos à própria subsistência. Tudo se passa como se a humanidade, em sua essência, tivesse herdado da vida uma ambiguidade constitutiva, a inclinação à liberdade e à individualidade por suas habilidades intelectuais, e a necessidade imperiosa de submissão ao coletivo sem o qual não há vida possível para o ser humano. A função fabuladora da inteligência vem responder exatamente a esse dilema, depende também da conclusão essencial de que o instinto simpatiza com a vida e significa, consequentemente, para os seres inteligentes, uma via de acesso à coesão própria às células e aos organismos que elas compõem.

Em se tratando de extrair dessas breves considerações alguma conclusão, defendemos que a relação estabelecida por Bergson com as ciências do social e com a antropologia depende sobremaneira de que se determine em profundidade o papel das noções de vida, hábito e instinto na abertura de $A s$ Duas Fontes da Moral e da Religião. Ali, o acompanhamento da explicação dos fundamentos da sociedade fechada e da moralidade que a sustenta, assentada na obrigação e no dever, assim como a definição bergsoniana da função fabuladora (que explica a gênese da religião), à luz de tais noções é indispensável para evitar um pré-julgamento de teses como a de relações instintivas permeando as ações inteligentes, para ficar apenas nesse exemplo. Tal acompanhamento possibilita enfrentar o problema que responde por uma incompreensão geral e histórica dessa obra, somente reencontrada e tomada a sério pela geração mais recente de pesquisadores que se dedicam ao filósofo da duração. Possibilita, mais explicitamente, compreender como a moral fechada e a religião estática implicam em si mesmas a abertura e o dinamismo que possibilitam aos homens superar os limites da natureza - e assim da própria humanidade como espécie. Todas as reflexões bergsonianas sobre o papel dos místicos, fonte das maiores resistências do meio filosófico do pós-guerra francês ao seu pensamento, dependem da justa compreensão das dualidades operadas pelo livro. Ao tomar a sério o fato de que a humanidade é a espécie que leva ao limite a tendência intelectual, definindo-se pela inteligência, não é de se surpreender que as prescrições éticas da última obra de Bergson, assentadas na passagem do fechado ao aberto, repousem sobre a intermediação que a inteligência é capaz de efetivar entre o plano da espécie e o apelo dos indivíduos. Buscamos deixar claro aqui que essa passagem recebe da confrontação crítica e do diálogo com a sociologia e a antropologia o fomento necessário para articular a intepretação filosófica dos fenômenos 
sociais com a superação da natureza em direção à cultura que tais ciências tematizam em profundidade.

\section{Referências Bibliográficas}

Bergson, H. A Evolução Criadora. Trad. Bento Prado Neto. São Paulo: Martins Fontes, 2005. 1999. . Matéria e Memória. Trad. Paulo Neves. São Paulo: Martins Fontes, . La pensée et le mouvant. Ed. Critique sous la direction de F. Worms.

Paris: PUF, 2009.

. Les Deux Sources de la Morale et de la Religion. Ed. Critique sous la direction de F. Worms. Paris: PUF, 2008.

BOUANICHE, A. "L'original et le originaire, l'unité de la origine". In: WORMS, Frédéric (éd.). Annales bergsoniennes I: Bergson dans le siècle. Paris: PUF, 2002.

FRANÇOIS, A. Bergson, Schopenhauer, Nietzssche. Volonté et Réalité. Paris: PUF, 2008.

L'Évolution Créatrice de Bergson. Études et Comentaire. Paris: Vrin, 2010

KECK, F. "Bergson et l'anthropologie. Le problème de l'humanité dans le Deux Sources de la Morale et de la Religion”. In: WORMS, F (Ed.) Annales bergsonienes I. Bergson dans le siècle. Paris: PUF, 2002, p. 195-214.

LÉVI-STRAUSS, C. O Totemismo Hoje. Lisboa: Edições 70, 1986.

TEIXEIRA, R. H. "A obrigação do ponto de vista de Bergson. Alguns aspectos de As Duas Fontes da Moral e da Religião". In: Princípios, v.21, n.35, Janeiro/Junho de 2014, p.351-387).

WORMS, F. Bergson ou les deux sens de la vie. Paris: PUF, 2004.

. "Le clos et le ouvert dans 'Les deux sources de la morale et de la religion': une distinction qui change tout". In: WATERLOT, G. Bergson et la religion. Nouvelles perspectives sur "Les deux sources de la morale et de la religion ». Paris: PUF, 2008. 